\title{
Dead space ventilation in normal children and children with obstructive airways disease
}

\author{
A. A. KER R \\ Respiratory Unit, The Hospital for Sick Children, Great Ormond Street, London
}

\begin{abstract}
Kerr, A. A. (1976). Thorax, 31, 63-69. Dead space ventilation in normal children and children with obstructive airways disease. Anatomical dead space was measured in 72 normal children aged from 5 to 16 years, using the single breath method. There was a linear increase in this measurement with height, weight, and end-inspiratory lung volume.

Physiological dead space was measured in 52 normal children using the Bohr equation and substituting a rebreathing $\mathrm{PCO}_{2}$ for alveolar $\mathrm{PCO}_{2}$. There was a parallel increase in this measurement with height, weight, and end-inspiratory lung volume. The difference between the two dead space measurements constitutes the alveolar dead space and was constant over the whole age range at $45 \pm 22 \mathrm{ml}$.

The ratio of physiological dead space to tidal volume was $33 \cdot 6 \pm 4.6 \%$ and was unaltered by age or change in lung volume.

The effect of airways obstruction on the dead space volumes was studied in 36 children with asthma and 28 with cystic fibrosis. Physiological dead space increased with increasing airways obstruction. Anatomical dead space remained constant in spite of marked increases in lung volume associated with the airways obstruction.
\end{abstract}

There is little published information on the various dead space volumes in children (Polgar and Promadhat, 1971). Hart, Orzalesi, and Cook (1963) measured the anatomical dead space in 73 normal subjects aged 4 to 42 years. No information is obtained from these data from both children and adults about the changes throughout childhood which might occur with lung growth. The commonly used nomogram values for this age range (Radford, 1955) are based on derived data from eight boys only (Robinson, 1938).

Similarly, there is little information on the physiological dead space in normal children and on the ratio of this to tidal volume (Beaudry, Wise, and Seely, 1967; Levison, Featherby, and Weng, 1970).

The following studies were undertaken to collect more normal data and, in particular, to compare anatomical and physiological dead space.

A study was also made of the changes in dead space volumes with airways obstruction due to asthma and cystic fibrosis.

\section{METHODS AND MATERIAL}

Studies were performed on 72 normal healthy children aged 5 to 16 years. They were all from the inner London area and were well at the time of study.
All measurements were made with the child sitting on a laboratory stool under resting conditions.

Anatomical dead space $\left(V_{D_{\text {anat }}}\right)$ was measured by a modification of the single breath method (Fowler, 1948). The electronically integrated expired volume from a Fleisch No. 1 pneumotachograph and the expired $\mathrm{CO}_{2}$ concentration from a VG Micromass 1 mass spectrometer were recorded on a $U-V$ recorder for at least three breaths. The dead space was measured from the point where the $\mathrm{CO}_{2}$ concentration had risen halfway to the initial alveolar level (Young, 1955). Allowance of $150 \mathrm{~ms}$ was made for the delay in gas analysis, and a further $15 \mathrm{ml}$ was subtracted for apparatus dead space. The pneumotachograph was calibrated by injecting through it $500 \mathrm{ml}$ from a large syringe.

The accuracy of this method of analysis was checked in 10 normal children, 10 children with asthma, and 10 with cystic fibrosis. This was done by drawing a perpendicular through the halfway point on the $\mathrm{CO}_{2}$ trace and measuring the areas $\mathrm{A}$ and $\mathrm{B}$ on the trace as shown in Figure 1. Ideally, these areas should be equal. They were cut out and weighed, and the error in placing the perpendicular was estimated in terms of displacement to either side of ideal. There was an overall mean shift of $0.14 \mathrm{~mm}$ to the left for this perpendicular. Even with the greatest 


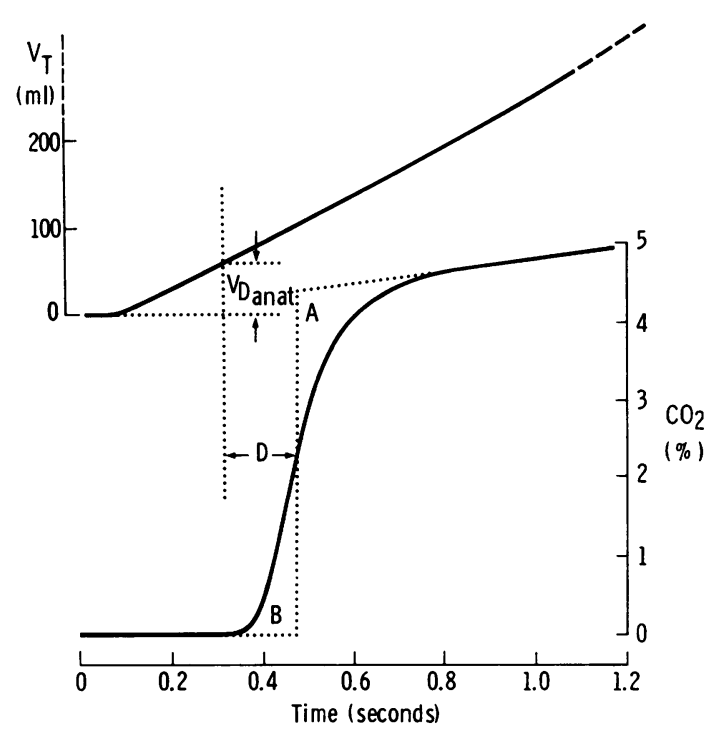

FIG. 1. Tidal volume trace $\left(V_{T}\right.$, above) and expired $\mathrm{CO}_{2}$ trace (below) showing the method used to measure anatomical dead space $\left(V_{D}\right.$ anat $)$. Ideally, the triangular areas $A$ and $B$ should be equal. In this study the perpendicular between the two areas was drawn so that it crossed the $\mathrm{CO}_{2}$ trace halfway between $0 \% \mathrm{CO}_{2}$ and the initial alveolar $\mathrm{CO}_{2}$ concentration. Using this method there was no significant difference in the areas. $D$ is the delay due to the sampling time of the $\mathrm{CO}_{2}$ analyser.

displacement, however, there was no measurable underestimation of the volume of $V_{D}$ anat. The method was further checked by injecting a $\mathrm{CO}_{2}$ mixture through an added dead space and comparing the recorded $V_{D}$ of this with the actual added volume measured by filling it with water. There was a $1 \%$ overestimate for an added dead space of $95 \mathrm{ml}$ and a $9 \%$ overestimate for a $64 \mathrm{ml}$ dead space. The mean coefficient of variation for $V_{D}$ anat measurement in 12 children who had five or more breaths analysed was $10 \cdot 1 \%$.

The physiological dead space $\left(\mathrm{V}_{\mathrm{D}}\right.$ phys) was measured using the Bohr equation (Comroe et al., 1962). An accurately timed mixed expired gas collection was made over at least 3 minutes. The volume was measured by the pneumotachograph. This was calibrated immediately after the collection by taking a second collection through it into a wet spirometer (C. F. Palmer Ltd, London), the volume of which was measured and corrected to BTPS. The $\mathrm{CO}_{2}$ and $\mathrm{O}_{2}$ content of the final mixed expired gas collection was measured with the mass spectrometer. The end-tidal $\mathrm{PCO}_{2}$ was recorded during the collection, and if this varied by more than $5 \%$, the collection was discarded. Alveolar $\mathrm{PCO}_{2}$ was measured indirectly by a rebreathing method using mixtures of $\mathrm{CO}_{2}$ in $\stackrel{\overrightarrow{\mathrm{F}}}{\stackrel{\vec{\rho}}{+}}$ air (Collier, 1956). Tracings were accepted only if a든 true $\mathrm{CO}_{2}$ equilibration plateau was obtained between $\frac{\overline{\bar{N}}}{\overline{\mathrm{S}}}$ 10 and 20 seconds from the start of rebreathing. Duplicate estimates were made, and from these the $\mathrm{O}$ mixed venous $\mathrm{PCO}_{2}$ was obtained; $6 \mathrm{mmHg}$ wase subtracted to give the arterial $\mathrm{PCO}_{2}$, which was $\vec{\circ}$ assumed to equal alveolar $\mathrm{PCO}_{2}$. The mean arterial $\mathrm{PCO}_{2}$ measured by this method in $\mathbf{5 2}$ normal children $\vec{\omega}$ was $39.3 \mathrm{mmHg}$ with a standard deviation of $3 \cdot 1 \mathrm{mmHg}$. The coefficient of variation for $V_{D}$ phys $\times$ measurement was $6.0 \%$ in one adult tested four ${ }^{\omega}$ times.

During the 3 minute collection for the measurement $\mathcal{E}^{\circ}$ of $V_{D}$ phys, minute ventilation $\left(\dot{V}_{E}\right)$, tidal volumeo $\left(V_{T}\right)$, and breathing frequency (f) were recorded. From these, alveolar minute ventilation $\left(\dot{V}_{A}=\dot{V}_{E}-T\right.$ $\dot{\mathrm{V}}_{\mathrm{D}}$ anat $)$ and alveolar dead space $\left(\mathrm{V}_{D_{A}}=\mathrm{V}_{\mathrm{D}}\right.$ phys $-\frac{\mathbb{O}}{\mathrm{O}}$ $V_{D \text { anat }}$ ) were calculated.

Thoracic gas volume (TGV) was measured by the plethysmographic method of Dubois et al. (1956) $\vec{\bullet}$ End-inspiratory lung volume (EILV) was taken as the sum of TGV and $V_{T}$.

\section{RESULTS}

Anatomical dead space $\left(V_{D}\right.$ anat $)$ measurements were obtained in 72 normal children and the results are illustrated in Figure 2.

There were 52 children in whom a satisfactory steady-state gas collection with constant end-tidab $\mathrm{PCO}_{2}$ was obtained. Data from these children onlyo were included in results of $V_{D}$ phys and ventilation

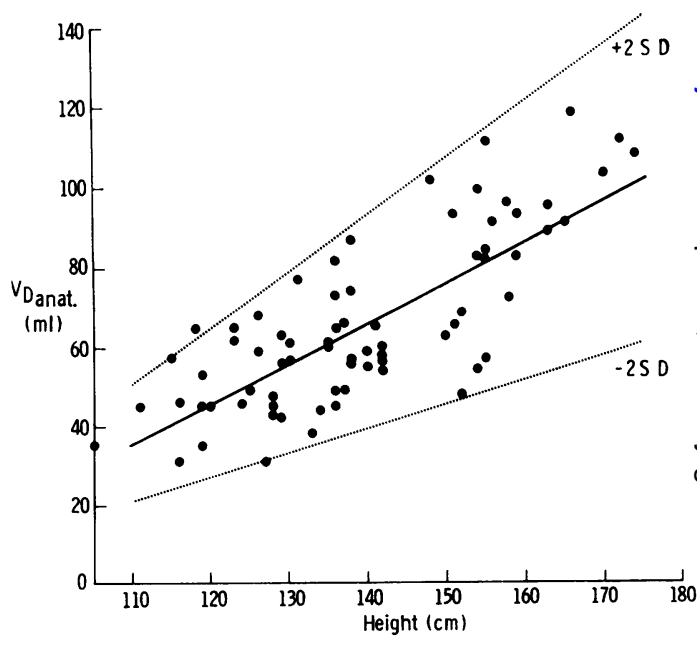

FIG. 2. Anatomical dead space ( $V_{D}$ anat $)$ plotted agains height for 72 healthy children. The regression line and 2 standard deviations from the regression are shown. 
measurements. The results of $V_{D}$ phys measurement in this group of children are shown in Figure 3.

EILV is the most appropriate lung volume to which to relate $V_{D}$, as it represents the actual lung volume from which $V_{D}$ is measured. The regression equations and correlation coefficients for all these data are given in Table $I$.

There was no significant difference in the slopes of the regression lines for $V_{D}$ anat and $V_{D}$ phys $(P>0.05)$, and the mean difference between them was $44.5 \mathrm{ml}$.

Table II shows the mean values for $\mathrm{f}, \mathrm{PaCO}_{2}$, $R, V_{D \text { anat }} / V_{T}, V_{D \text { phys }} / V_{T}, V_{D A}$ and $V_{D A} / V_{A}$. None of these varied significantly with age.

Tidal volume $\left(\mathrm{V}_{\mathrm{T}}\right)$ showed a linear relationship to height:

$$
\mathrm{V}_{\mathrm{T}}(\mathrm{ml})=4 \cdot 19 \times \text { Height }(\mathrm{cm})-206 \cdot 6(\mathrm{r}=0 \cdot 596)
$$

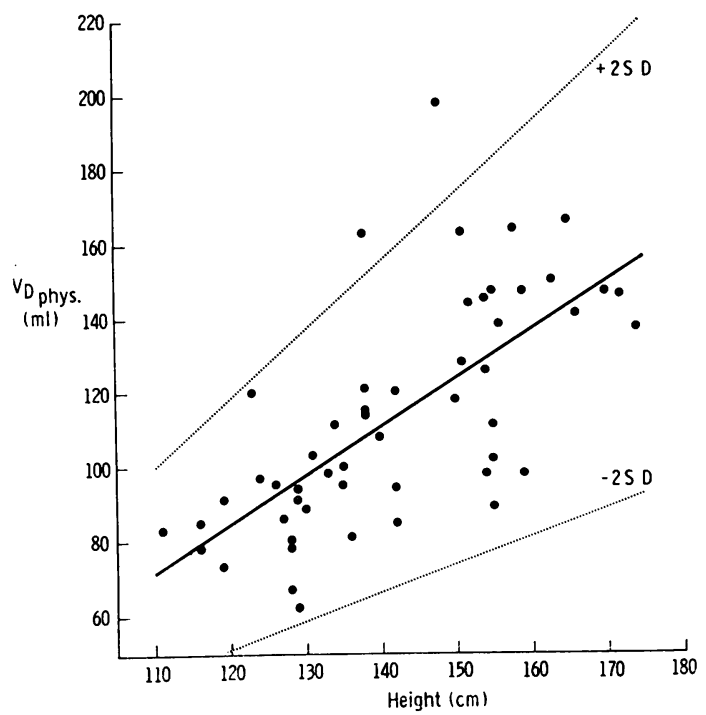

FIG. 3. Physiological dead space $\left(V_{D}\right.$ phys $)$ plotted against height for 52 healthy children. The regression line and 2 standard deviations from the regression are shown.

T A B L E I RELATIONSHIPS BETWEEN RESPIRATORY DEAD SPACE
VOLUMES AND HEIGHT, WEIGHT, AGE, AND ENDINSPIRATORY LUNG VOLUME IN NORMAL CHILDREN

\begin{tabular}{c|c|c}
\hline Regression Equation & r & $\begin{array}{c}\text { Co-efficient } \\
\text { of Variation } \\
\text { of Regression }\end{array}$ \\
\hline VD anat $(\mathrm{ml})=1.018 \times$ Height $(\mathrm{cm})-76.2$ & 0.774 & $20.4 \%$ \\
VD anat $(\mathrm{ml})=3.716 \times$ Age $($ years) +27.0 & 0.552 & $26.7 \%$ \\
VD anat (ml) $=1.374 \times$ Weight $(\mathrm{kg})+16.5$ & 0.755 & $21.3 \%$ \\
VD anat $(\mathrm{ml})=0.028 \times$ EILV $(\mathrm{ml})+7.3$ & 0.800 & $20.3 \%$ \\
VD phys (ml) $=1.307 \times$ Height $(\mathrm{cm})-72.5$ & 0.687 & $19.7 \%$ \\
VD phys (ml) $=1.660 \times$ Weight $(\mathrm{kg})+51.1$ & 0.672 & $20.1 \%$ \\
VD phys (ml) $=0.031 \times$ EILV $(\mathrm{ml})+45.1$ & 0.671 & $20.1 \%$ \\
\hline
\end{tabular}

T A B L E I I

DATA ON VENTILATION IN 52 NORMAL CHILDREN

\begin{tabular}{l|cc}
\hline & Mean & $\begin{array}{c}\text { Standard } \\
\text { Deviation }\end{array}$ \\
\hline f (breaths/minute) & 17 & 3.9 \\
PaCO $_{2}(\mathrm{mmHg})$ & $39 \cdot 3$ & 3.1 \\
R & $0 \cdot 751$ & 0.076 \\
VD anat/Vr (\%) & 18.0 & 5.0 \\
VD phys/Vr (\%) & 33.6 & 4.6 \\
VDA (ml) & 44.7 & 22.4 \\
VDA/VA (\%) & 14.0 & 5.7 \\
\hline
\end{tabular}

Alveolar ventilation also had a significant correlation with height:

$$
\dot{\mathrm{V}}_{\mathrm{A}}(\mathrm{l} / \mathrm{min})=0.034 \times \text { Height }+0.395(\mathrm{r}=0.548) \text {. }
$$

Satisfactory data were obtained in 36 children with bronchial asthma, in eight of whom second measurements were obtained at a time when the degree of airways obstruction had altered. In the total group of asthmatic children, $V_{D}$ anat remained at the volume expected for height but was diminished in relation to EILV (Fig. 4). The diminution relative to lung volume was greater with more severe degrees of hyperinflation. These findings were consistent with those in the eight children in whom serial studies were performed. In spite of a mean increase in EILV of $604 \pm 348 \mathrm{ml}$ (1SD), there was an increase in $V_{D}$ anat of only $0.63 \pm 11.2 \mathrm{ml}(1 \mathrm{SD})$. By contrast, the rise in $V_{D}$ phys was either in proportion to the rise in lung volume or greater than would be expected (Fig. 5).

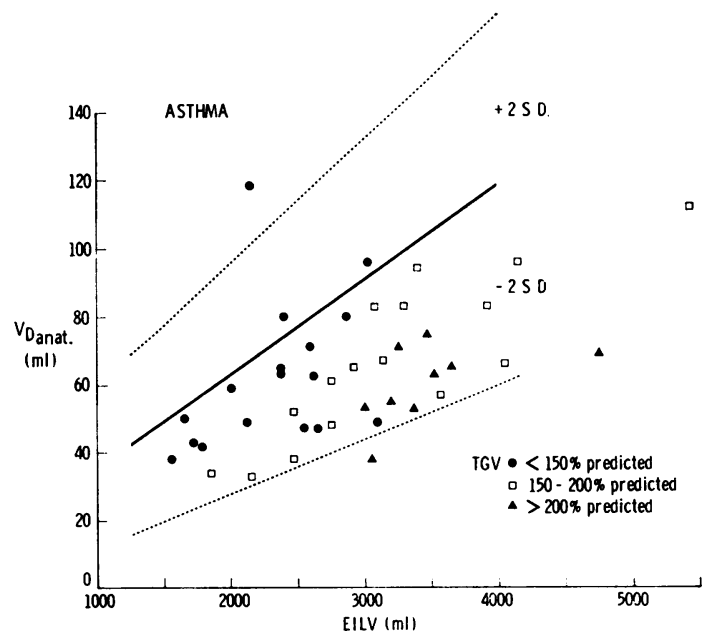

FIG. 4. Anatomical dead space ( $V_{D}$ anat $)$ plotted against end-inspiratory lung volume (EILV) in 42 asthmatic children. The degree of hyperinflation is indicated by the increase in thoracic gas volume (TGV), which is shown as a percentage of that predicted for height. The mean $\pm 2 S D$ lines are shown for the regression of $V_{D}$ anat against EILV in healthy children. 


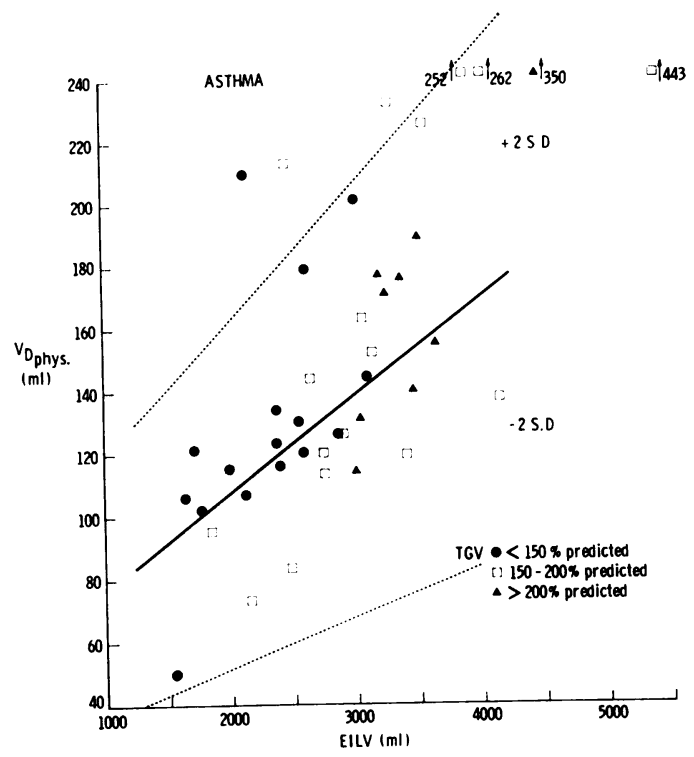

FIG. 5. Physiological dead space $\left(V_{D}\right.$ phys $)$ plotted against end-inspiratory lung volume (EILV) in 42 asthmatic children. The degree of hyperinflation is indicated by the increase in thoracic gas volume (TGV), which is shown as a percentage of that predicted for height. The mean $\pm 2 S D$ lines are shown for the regression of $V_{D}$ phys against EILV in healthy children.

The results of $V_{D}$ measurement in 28 children with cystic fibrosis are shown in Figures 6 and 7. The relative decrease in $V_{D}$ anat with increase in EILV was less apparent, but most values did lie in the lower half of the normal range. There were large increases in $V_{D}$ phys with increasing severity of disease as indicated by increase in lung volume.

\section{DISCUSSION}

It has been shown that the respiratory dead space measured by relating expired gas concentration changes to expired volume $\left(V_{D}\right.$ anat $)$ is the same for all respiratory gases (Bartels et al., 1954). It is, therefore, reasonable to compare the values of $V_{D \text { anat }}$ obtained in the present study with earlier data using the original nitrogen technique (Fowler, 1948). The only data available over a similar age range are from studies by Hart et al. (1963) and Beaudry et al. (1967). These results are shown in Figure 8. The data on adult males from Fowler (1948) are also shown for comparison. The results from other studies tend to fall between the regressions for the two different measurements of $V_{D}$ in the present study. An apparent decrease in $V_{D}$ anat can occur with breathholding (Bartels et al., 1954; Shepard, Campbell,

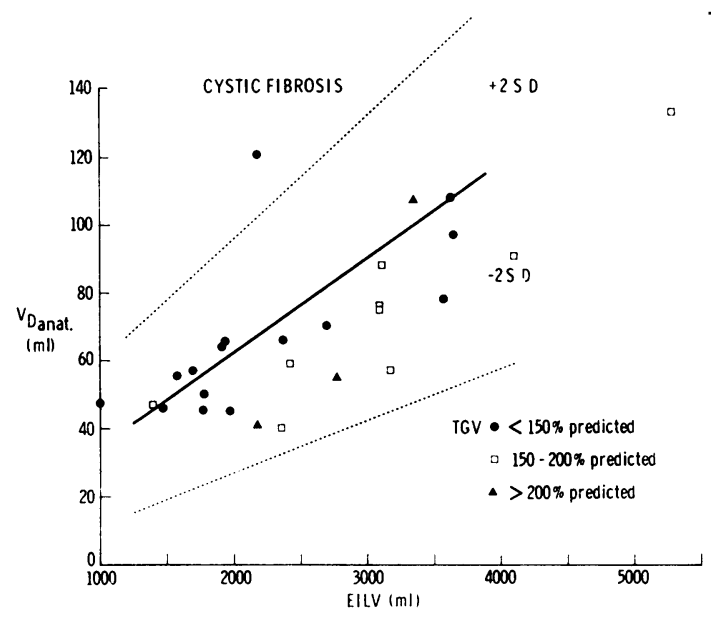

FIG. 6. Anatomical dead space $\left(V_{D}\right.$ anat $)$ plotted against end-inspiratory lung volume (EILV) in 28 children with cystic fibrosis. The degree of hyperinflation is indicated by $\vec{\theta}$ the increase in thoracic gas volume (TGV), which is showno as a percentage of that predicted for height. The mean $\pm 2 S D$ lines are shown for the regression of $V_{D}$ anat against EILV in healthy children.

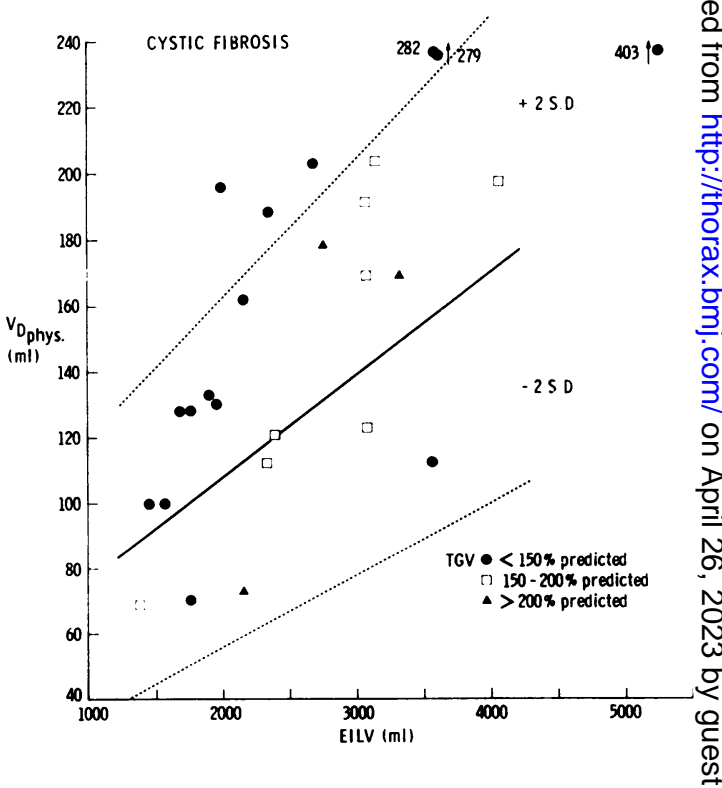

FIG. 7. Physiological dead space $\left(V_{D}\right.$ phys $)$ plotted against end-inspiratory lung volume (EILV) in 28 children with cystic fibrosis. The degree of hyperinflation is indicated by the increase in thoracic gas volume (TGV), which is shown as a percentage of that predicted for height. The mean $\pm 2 S D$ lines are shown for the regression of $V_{D}$ phys agains EILV in healthy children. 


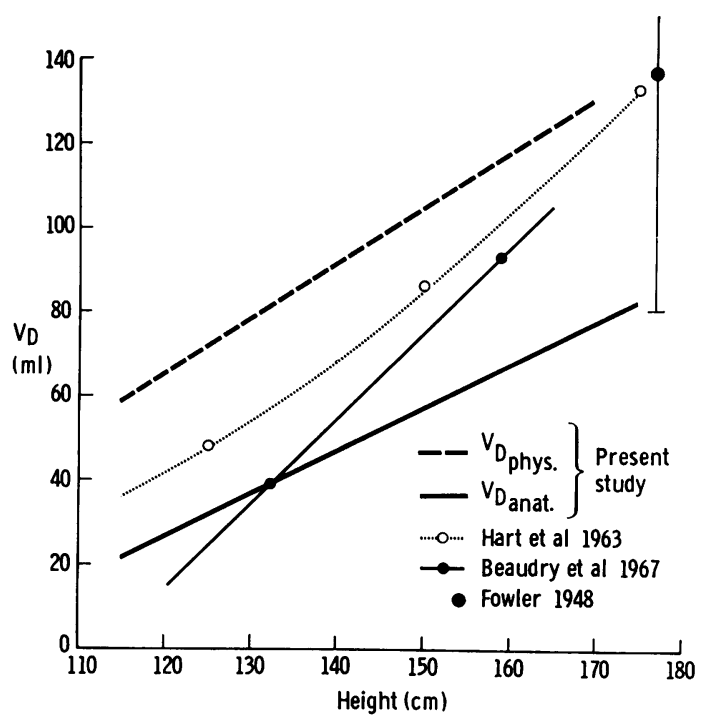

FIG. 8. Comparison of dead space $\left(V_{D}\right)$ measurement in healthy subjects. The values from Fowler (1948) are the mean and $2 S D$ for 45 adult males using the $N_{2}$ single breath method. The other data are from Beaudry et al. (1967), using the Bohr equation in children, and from Hart et al. (1963), using the $N_{2}$ single breath method in children and adults.

Martin, and Enns, 1957). Alternatively, increasing the breathing frequency may cause an apparent increase in $V_{D}$ anat, and a real increase in $V_{D}$ anat occurs with increased lung volume (Shepard et al., 1957; Lifshay, Fast, and Glazier, 1971). From the data available, none of these factors appears to contribute significantly to the variation in $V_{D}$ results between the present study and earlier work.

It is accepted in adults that $V_{D \text { anat }}$ and $V_{D}$ phys are virtually identical in normal lungs (Comroe et al., 1962). That a similar relationship holds for children has been assumed (Polgar and Promadhat, 1971), but no direct measurement of both types of dead space in the same children has previously been made. The present study shows a mean difference of $44.5 \mathrm{ml}$ between the regression lines for $V_{D}$ anat and $V_{D}$ phys. This difference $\left(V_{D} A\right)$ remains constant with age, and it might be expected to become a smaller proportion of $\mathrm{V}_{\mathrm{A}}$ in older children. This does not appear to be so. $V_{D_{A}} / V_{A}$ shows no correlation with age, height or lung volume, presumably because there is a wide variation in $V_{D}$ a measurement.

The use of $6 \mathrm{mmHg}$ as the a- $\overline{\mathrm{v}}$ difference for $\mathrm{PCO}_{2}$ has recently been questioned by McEvoy, Jones, and Campbell (1974). They found that $10 \mathrm{mmHg}$ was a more appropriate figure in adults with normal $\mathrm{PCO}_{2}$ and when the blood was fully oxygenated. The Collier method for rebreathing $\mathrm{PCO}_{2}$, as used in the present study, uses a mixture of $\mathrm{CO}_{2}$ in air. At equilibration the $\mathrm{O}_{2}$ content of the bag was about $16 \%$ so that $\mathrm{Hb}$ would not be fully saturated. In these circumstances the $\mathrm{PCO}_{2}$ would be lower than if it were saturated, provided the $\mathrm{CO}_{2}$ content remains constant. Accordingly, the $a-\bar{v}$ difference for $\mathrm{PCO}_{2}$ would be expected to be lower in the present study than in the work of McEvoy et al. (1974). This is borne out by the fact that the range of $\mathrm{PaCO}_{2}$ in these normal children, as estimated by the rebreathing method, is the same as is generally accepted for direct measurement. However, in children with airways obstruction, the $a-\bar{v}$ difference may have been greater than $6 \mathrm{mmHg}$ and, if so, this would result in an overestimate in estimated $\mathrm{PaCO}_{2}$ and $\mathrm{V}_{\mathrm{D} \text { phys }}$ in this group.

The ratio of wasted ventilation to tidal volume $\left(V_{D}\right.$ phys $\left./ V_{T}\right)$ has been cited as a useful index in intensive respiratory management (Downes, Fulgencio, and Raphaely, 1972) and as a sensitive index of early changes with disease, especially during exercise challenge (Levine et al., 1970). A normal value of $30 \%$ is usually quoted for this ratio (Polgar and Promadhat, 1971). The values obtained in the present study show a wide range, which is comparable to data reported in studies on normal infants, older children, and adults (Table III).

Recently, Harris et al. (1973) pointed out the inapplicability of relating $V_{D}$ phys to $V_{T}$ only. In their study in adults, they defined a multiple regression of $V_{D}$ on age, height, $V_{T}$ and the reciprocal of respiratory frequency which gave the best prediction of $V_{D}$ phys. In the present study a similarly improved correlation was obtained by using simple regressions of $V_{D}$ phys on height, weight, and lung volume (EILV) rather than the ratio of $V_{D}$ phys to $V_{T}$.

There is a significant correlation between $V_{T}$ and height, and these data agree with those of Levison $e t$ al. (1970). The estimated figures given by Cook and Motoyama (1968) are too low. The alveolar ventilation data $\left(\dot{\mathrm{V}}_{\mathrm{A}}\right)$ from this study are significantly higher than the measurements of Levison et al. (1970) and the estimates of Cook and Motoyama (1968). Both $V_{T}$ and $\dot{V}_{A}$ are increased if not taken under basal conditions, and this probably accounts for the discrepancies. The normal values for the respiratory quotient ( $R$, Table II) indicate that this increase in ventilation was appropriate to the increase in oxygen consumption above the basal state.

The changes in $V_{D}$ with disease are of considerable interest. It is well established that $V_{D}$ phys is increased in both asthma and cystic fibrosis (Downes et al., 1972). Comparison of Figs. 5 and 7 shows that in cystic fibrosis the $V_{D}$ phys increase is less dependent on the degree of hyperinflation (as shown by the rise in EILV) than it is in asthma. This is presumably 
T A B L E I I I

COMPARISON OF VD phys/Vt IN NORMAL SUBJECTS IN THE SITTING POSITION

\begin{tabular}{|c|c|c|c|c|}
\hline Study & Age Range & Number & Mean & Standard Deviation \\
\hline $\begin{array}{l}\text { Mellemgaard (1966) } \\
\text { Mellemgaard (1966) } \\
\text { Fowler (1948) } \\
\text { Raine and Bishop (1963) } \\
\text { Raine and Bishop (1963) }\end{array}$ & $\begin{array}{l}15-40 \text { years } \\
40-77 \text { years } \\
19-38 \text { years } \\
17-40 \text { years } \\
40-66 \text { years }\end{array}$ & $\begin{array}{l}40 \\
40 \\
45 \\
32 \\
17\end{array}$ & $\begin{array}{l}29 \cdot 1 \\
33 \cdot 7 \\
25 \cdot 9 \\
23 \cdot 8 \\
26 \cdot 1\end{array}$ & $\begin{array}{l}7 \cdot 2 \\
7 \cdot 1 \\
7 \cdot 6 \\
6 \cdot 2 \\
6 \cdot 4\end{array}$ \\
\hline $\begin{array}{l}\text { Present study } \\
\text { Beaudry et al. (1967) } \\
\text { Levison et al. (1970) }\end{array}$ & $\begin{array}{l}7-16 \text { years } \\
11 \cdot 55 \text { years (mean) } \\
7-19 \text { years }\end{array}$ & $\begin{array}{l}52 \\
18 \\
42\end{array}$ & $\begin{array}{l}33 \cdot 6 \\
26 \cdot 1 \\
29\end{array}$ & $\begin{array}{c}4 \cdot 6 \\
7 \cdot 3 \\
\text { not given }\end{array}$ \\
\hline $\begin{array}{l}\text { Strang (1961) } \\
\text { Nelson et al. (1962) } \\
\text { Cook et al. (1955) }\end{array}$ & $\begin{array}{l}0-8 \text { days } \\
0-42 \text { days } \\
0-7 \text { days }\end{array}$ & $\begin{array}{r}9 \\
25 \\
16\end{array}$ & $\begin{array}{l}57 \\
25 \\
32\end{array}$ & $\begin{array}{r}8 \\
7 \\
12\end{array}$ \\
\hline
\end{tabular}

because cystic fibrosis is a patchy disease (Bodian, 1952), and consequently there is a localized increase in the ventilation:perfusion ratio which results in increased $V_{D}$ phys. In asthma, on the other hand, there is more diffuse airways obstruction, resulting in diminished $\dot{\mathrm{V}}_{\mathrm{A}}$ without gross ventilation:perfusion inequality until hyperinflation is severe (TGV more than $150 \%$ predicted, in Fig. 5).

The changes in $V_{D}$ anat are different. In asthma, the individual $\mathbf{V}_{\mathbf{D}}$ anat values are all within the normal range for height but are low in relation to EILV. In normal lungs, increased lung volume causes an increase in $V_{D}$ anat (Shepard et al., 1957; Lifshay et al., 1971). This did not occur in those patients in whom the increased lung volume was due to airways obstruction. There are two possible explanations for this:

(1) In asthma, narrowing of the small airways produces poor alveolar emptying during expiration. This results in air trapping at alveolar level with increase in the total lung volume. Such an increase in lung volume is not associated with reduced intrapleural pressure and increased radial traction on the large airways, as occurs when a person with normal lung mechanics increases his lung volume. Consequently, the asthmatic with hyperinflated lungs will tend not to have increased large airway volume.

(2) During attacks of asthma, the smooth muscle in the tracheal and bronchial walls also contracts. Olsen, Stevens, and McIlroy (1967) showed in cats that this results in reduced airway wall compliance. This would reduce the effect that breathing at a higher lung volume has on $V_{D}$ anat by preventing the expansion of the large airways that normally occurs with increase in lung volume. From the present data it is not apparent which of these factors is the more important.

I am very grateful to Dr. D. Hatch for helpful advice during the course of these studies.

The work was supported by a grant from the Medical Research Council.

\section{REFERENCES}

Bartels, J., Severinghaus, J. W., Forster, R. E., Briscoe,W. A., and Bates, D. V. (1954). The respiratory deadT space measured by single breath analysis of oxygen, ${ }^{\circ}$ carbon dioxide, nitrogen or helium. Journal of Clinical Investigation, 33, 41.

Beaudry, P. H., Wise, M. B., and Seely, J. E. (1967). Respiratory gas exchange at rest and during exercise 6 in normal and asthmatic children. American Reviewo of Respiratory Disease, 95, 248.

Bodian, M., Ed. (1952). Fibrocystic Disease of the Pancreas. Heinemann, London.

Collier, C. R. (1956). Determination of mixed venous $\mathrm{CO}_{2}$ tensions by rebreathing. Journal of Applied Physiology, 9, 25.

Comroe, J. H., Jr., Forster, R. E., II, DuBois, A. B., $\overrightarrow{\bar{Q}}$ Briscoe, W. A., and Carlsen, E. (1962). The Lung:윽 Clinical Physiology and Pulmonary Function Tests, 2nd edition. Year Book Medical Publishers, Chicago.

Cook, C. D., Cherry, R. B., O'Brien, D., Karlberg, P., and Smith, C. A. (1955). Studies of respiratory physiology in the newborn infant. I. Observations on음 normal premature and full-term infants. Journal of Clinical Investigations, 34, 975.

and Motoyama, E. K. (1968). Respiratory physiology in infants and children. In Anesthesia for Infants ando Children, edited by R. M. Smith, 3rd edition, p. 32 .윽 C. V. Mosby, St. Louis.

Downes, J. J., Fulgencio, T., and Raphaely, R. C. (1972).을 Acute respiratory failure in infants and children. $D$ Pediatric Clinics of North America, 19, 423.

Dubois, A. B., Botelho, S. Y., Bedell, G. N., Marshall, R., and Comroe, J. H., Jr. (1956). A rapid plethysmo-o graphic method for measuring thoracic gas volume: a comparison with a nitrogen washout method for measuring functional residual capacity in normal subjects. Journal of Clinical Investigation, 35, 322.

Fowler, W. S. (1948). Lung function studies. II. Theo respiratory dead space. American Journal of Physio$\log y, 154,405$.

Harris, E. A., Hunter, M. E., Seelye, E. R., Vedder, M.; and Whitlock, R. M. L. (1973). Prediction of the physiological dead-space in resting normal subjects. Clinical Science and Molecular Medicine, 45, 375.

Hart, M. C., Orzalesi, M. M., and Cook, C. D. (1963) Relation between anatomic respiratory dead spaceo and body size and lung volume. Journal of Applied Physiology, 18, 519. 
Levine, G., Housley, E., MacLeod, P., and Macklem, P. T. (1970). Gas exchange abnormalities in mild bronchitis and asymptomatic asthma. New England Journal of Medicine, 282, 1277.

Levison, H., Featherby, E. A., and Weng, T. R. (1970). Arterial blood gases, alveolar-arterial oxygen difference, and physiologic dead space in children and young adults. American Review of Respiratory Disease, 101, 972.

Lifshay, A., Fast, C. W., and Glazier, J. B. (1971). Effects of changes in respiratory pattern on physiological dead space. Journal of Applied Physiology, 31, 478.

McEvoy, J. D. S., Jones, N. L., and Campbell, E. J. M. (1974). Mixed venous and arterial Pco2. British Medical Journal, 4, 687.

Mellemgaard, K. (1966). The alveolar-arterial oxygen difference: its size and components in normal man Acta Physiologica Scandinavica, 67, 10.

Nelson, N. M., Prod'hom, L. S., Cherry, R. B., Lipsitz, P. J., and Smith, C. A. (1962). Pulmonary function in the newborn infant. I. Methods: Ventilation and gaseous metabolism. Pediatrics, 30, 963.

Olsen, C. R., Stevens, A. E., and McIlroy, M. B. (1967). Rigidity of tracheae and bronchi during muscular constriction. Journal of Applied Physiology, 23, 27.
Polgar, G. and Promadhat, V. (1971). Pulmonary Function Testing in Children: Techniques and Standards. Saunders, Philadelphia.

Radford, E. P., Jr. (1955). Ventilation standards for use in artificial respiration. Journal of Applied Physiology, 7,451 .

Raine, J. M. and Bishop, J. M. (1963). A-a difference in $\mathrm{O}_{2}$ tension and physiological dead space in normal man. Journal of Applied Physiology, 18, 284.

Robinson, S. (1938). Experimental studies of physical fitness in relation to age. Arbeitsphysiologie, 10, 251.

Shepard, R. H., Campbell, E. J. M., Martin, H. B., and Enns, T. (1957). Factors affecting the pulmonary dead space as determined by single breath analysis. Journal of Applied Physiology, 11, 241.

Strang, L. B. (1961). Alveolar gas and anatomical deadspace measurements in normal newborn infants. Clinical Science, 21, 107.

Young, A. C. (1955). Dead space at rest and during exercise. Journal of Applied Physiology, 8, 91 .

Requests for reprints to: Dr. A. A. Kerr, Respiratory Unit, The Hospital for Sick Children, Great Ormond Street, London WC1N 3JH. 